\title{
Risk of a coronary event in patients after ischemic stroke or transient ischemic attack
}

\author{
Ivan Poledník (®, Jakub Sulzenko @, Petr Widimsky @
}

Department of Cardiology, Third Faculty of Medicine, Charles University and University Hospital Kralovske Vinohrady; Prague-Czech Republic

\section{ABSTRACT}

Coronary artery disease (CAD) together with stroke are the leading causes of death worldwide, and together, they pre-sent a health and economic burden. Ischemic stroke survivors and patients who suffered transient ischemic attack (TIA) have a higher prevalence of coronary atherosclerosis, and they have a relatively high risk of myocardial infarcti-on and nonstroke vascular death. Pubmed was searched for studies focused on investigating coronary atherosclerosis in ischemic stroke survivors or patients who suffered TIA and their cardiovascular risk assessment. There were corona-ry plaques in $48 \%-70 \%$ of stroke survivors without a known history of CAD, and significant stenosis of at least one coronary artery can be found in $31 \%$ of these patients. CAD is a major cause of morbidity and mortality in stroke survivors. Detection and treatment of silent CAD may improve the long-term outcome and survival of these patients.

Key words: stroke, coronary artery disease, atherosclerosis, cardiovascular risk, myocardial infarction, cerebral infarction

Cite this article as: Poledník I, Sulzenko J, Widimsky P. Risk of a coronary event in patients after ischemic stroke or transient ischemic attack. Anatol J Cardiol 2021; 25: 152-5.

\section{Introduction}

Coronary artery disease (CAD) together with stroke are the leading causes of death worldwide (1). There is a close connection between the diseases because they share common risk factors and similar pathophysiology frequently on the basis of atherosclerosis. Recent studies have shown that patients who survive an acute ischemic stroke or transient ischemic attack (TIA) have a higher prevalence of coronary atherosclerosis. Furthermore, they are prone to developing acute coronary syndrome (ACS) (2). Therefore, it is necessary to identify, control, and reduce vascular risk factors to a minimum. There is still no consensus on whether stroke survivors should undergo routine screening for CAD.

\section{Methods}

A Pubmed search was conducted in search of studies focusing on the investigation of CAD in patients after ischemic stroke.
The following keywords were used: "coronary atherosclerosis," "stroke," "cerebral infarction," and "coronary artery disease." References for each publication were checked for additional studies. A total of 10 studies were found to be relevant and were reviewed. In some of these studies [Rokey et al. (3), Love et al. (4)], we excluded all patients with previously known CAD. Then, we used simple arithmetic mean to calculate the prevalence of significant coronary stenosis among stroke survivors. A similar strategy was used in the calculation of the prevalence of coronary atherosclerosis in patients with significant carotid stenosis.

\section{Risk factors}

Common risk factors for developing atherosclerosis in coronary and intracranial arteries include high blood cholesterol, high blood pressure, diabetes mellitus, smoking, physical inactivity, and an unhealthy diet. However, there are significant differences among how these factors affect the development of these diseases. For example, a high level of low-density lipopro-

Address for Correspondence: Ivan Poledník, MD, Department of Cardiology, Third Faculty of Medicine, Charles University and University Hospital Kralovske Vinohrady; Prague-Czech Republic

Phone: 00420606647144 E-mail: ivan.polednik@fnkv.cz

Accepted Date: 14.01.2021 Available Online Date: 22.02.2021

(C) Copyright 2021 by Turkish Society of Cardiology - Available online at www.anatoljcardiol.com DOI:10.5152/AnatolJCardiol.2021.75548 


\section{HIGHLIGHTS}

- Ischemic stroke survivors and patients who suffered transient ischemic attack have a higher risk of developing acute coronary syndrome. Significant stenosis of at least one coronary artery can be found in $31 \%$ of these patients. Detection and treatment of silent CAD may improve the long-term outcome and survival of these patients.

teins is a dominant risk factor for developing atherosclerosis in coronary arteries, whereas it is less important for the risk of stroke (5). On the contrary, disorders of heart rhythm, especially atrial fibrillation, are more relevant to ischemic stroke. Identifying and controlling these risk factors is necessary for the primary prevention of developing CAD or stroke.

Prevalence of coronary atherosclerosis among stroke survivors or patients who suffered TIA with no history of coronary heart disease

Recent studies have assessed the prevalence of CAD in stroke survivors using invasive and noninvasive techniques. Amarenco et al. (6) analyzed coronary angiography in 315 patients with no known coronary heart disease, who were admitted with nonfatal cerebral infarction. Among them, coronary plaques were found in $61.9 \%$, and coronary stenosis $>50 \%$ was found in at least one vessel in $25.7 \%$ of the patients (6). In a study of the South Korean stroke population using computed tomography angiography, $70.4 \%$ of them were found to different degrees of coronary atherosclerosis, and $33.1 \%$ of them had significant stenosis (7). In an autopsy study by Gongora-Rivera in patients with fatal stroke, significant coronary stenosis was found in $29.6 \%$ of 267 patients (8).
More studies investigating the prevalence of coronary atherosclerosis in patients with cerebral infarction are shown in Table 1. On the basis of these studies, stroke survivors with no history of CAD have coronary plaques in approximately $48 \%$ $70 \%$, and significant stenosis (minimum of $50 \%$ ) of at least one of the coronary arteries can be found in $30.9 \%$ of them $(3,4,6-13)$.

The prevalence of coronary atherosclerosis is even higher in patients awaiting planned carotid artery stenting. Enomoto et al. in their studies performed coronary angiography among these patients, and significant coronary stenosis was found in $58 \%$ of them (Table 2) (14-17). However, some of these patients were neurologically asymptomatic.

\section{Morbidity and mortality of patients after stroke}

The main cause of morbidity and mortality in nonfatal stroke survivors or patients who suffered TIA is the recurrence of stroke. Nevertheless, a large group of these patients die from cardiac causes. A recent study has shown that the annual incidence of fatal myocardial infarction in stroke survivors is $2.2 \%$ (2). Amarenco et al. (18) followed up stroke survivors for five years in their study on the effects of statin treatment. Acute coronary events developed in $5.3 \%$ of the patients among which $24.2 \%$ were fatal (18). Dhamoon et al. (19) in their study also monitored patients after stroke for five years, who were living in the area of Northern Manhattan. The results of their study showed that recurrence of stroke caused death in $3.7 \%$ of the patients, whereas cardiac causes led to death in $6.4 \%$ of them (19).

\section{Cardiovascular risk assessment after stroke and conclusion}

Ischemic stroke survivors and patients who suffered TIA have a higher risk of developing ACS. It is still unclear whether these patients should undergo coronary artery examination. The American Heart Association/American Stroke Association issued a recommendation that the cardiovascular (CV) risk

Table 1. Prevalence of coronary atherosclerosis in stroke survivors and patients who suffered TIA without previously known CAD

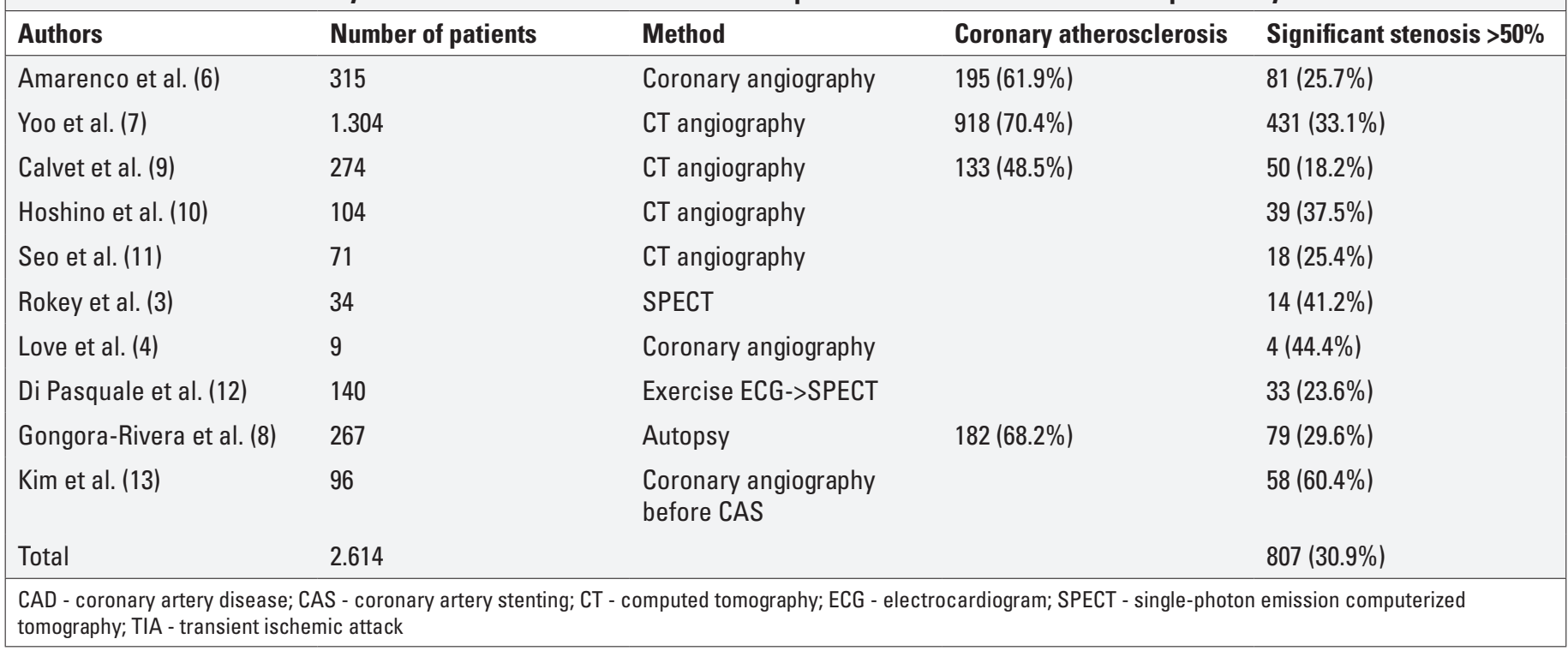




\begin{tabular}{|c|c|c|c|c|}
\hline Authors & Number of patients & Method & Coronary atherosclerosis & Significant stenosis $>\mathbf{5 0} \%$ \\
\hline Enomoto et al. (14) & 96 & Coronary angiography & & $39(40.6 \%)^{*}$ \\
\hline Hertzer et al. (16) & 200 & Coronary angiography & $173(86.5 \%)$ & $80(40.0 \%)$ \\
\hline Sulženko et al. (17) & 200 & Coronary angiography & $199(99.5 \%)$ & $155(77.5 \%)$ \\
\hline
\end{tabular}

should be assessed for each patient individually and those with the highest risk should undergo a noninvasive examination of the coronary arteries (20). This examination should also be performed in patients with significant symptomatic stenosis of carotid arteries. Independently of the CV risk of all stroke survivors or patients who suffered TIA, it is necessary to focus on their risk factors and their reduction to a minimum and therefore reach maximum prevention.

Institutional and financial support: This work was funded by the Charles University - Third Faculty of Medicine, project nr. 038.

\section{Conflict of interest: None declared.}

Peer-review: Internally peer-reviewed.

Author contributions: Concept - I.P., J.S., P.W.; Design - I.P., J.S., P.W.; Supervision - J.S., P.W.; Fundings - P.W.; Materials - I.P.; Data collection \&/or processing - I.P.; Analysis \&/or interpretation - I.P.; Literature search - I.P.; Writing - I.P.; Critical review - J.S., P.W.

\section{References}

1. Virani SS, Alonso A, Benjamin EJ, Bittencourt MS, Callaway CW, Carson AP, et al.; American Heart Association Council on Epidemiology and Prevention Statistics Committee and Stroke Statistics Subcommittee. Heart Disease and Stroke Statistics-2020 Update: A Report From the American Heart Association. Circulation 2020; 141: e139-596. [Crossref]

2. Touzé E, Varenne 0, Chatellier G, Peyrard S, Rothwell PM, Mas JL. Risk of myocardial infarction and vascular death after transient ischemic attack and ischemic stroke: a systematic review and meta-analysis. Stroke 2005; 36: 2748-55. [Crossref]

3. Rokey R, Rolak LA, Harati Y, Kutka N, Verani MS. Coronary artery disease in patients with cerebrovascular disease: a prospective study. Ann Neurol 1984; 16: 50-3. [Crossref]

4. Love BB, Grover-McKay M, Biller J, Rezai K, McKay CR. Coronary artery disease and cardiac events with asymptomatic and symptomatic cerebrovascular disease. Stroke 1992; 23: 939-45. [Crossref]

5. Kannel WB. Risk factors for atherosclerotic cardiovascular outcomes in different arterial territories. J Cardiovasc Risk 1994; 1: 333-9. [Crossref]

6. Amarenco P, Lavallée PC, Labreuche J, Ducrocq G, Juliard JM, Feldman $L$, et al. Prevalence of coronary atherosclerosis in patients with cerebral infarction. Stroke 2011; 42: 22-9. [Crossref]
7. Yoo J, Yang JH, Choi BW, Kim YD, Nam HS, Choi HY, et al. The frequency and risk of preclinical coronary artery disease detected using multichannel cardiac computed tomography in patients with ischemic stroke. Cerebrovasc Dis 2012; 33: 286-94. [Crossref]

8. Gongora-Rivera F, Labreuche J, Jaramillo A, Steg PG, Hauw JJ, Amarenco $P$. Autopsy prevalence of coronary atherosclerosis in patients with fatal stroke. Stroke 2007; 38: 1203-10. [Crossref]

9. Calvet D, Touzé E, Varenne 0, Sablayrolles JL, Weber S, Mas JL. Prevalence of asymptomatic coronary artery disease in ischemic stroke patients: the PRECORIS study. Circulation 2010; 121: 1623-9. [Crossref]

10. Hoshino A, Nakamura T, Enomoto $S$, Kawahito $H$, Kurata $H$, Nakahara $Y$, et al. Prevalence of coronary artery disease in Japanese patients with cerebral infarction: impact of metabolic syndrome and intracranial large artery atherosclerosis. Circ J 2008; 72: 404-8. [Crossref]

11. Seo WK, Yong HS, Koh SB, Suh SI, Kim JH, Yu SW, et al. Correlation of coronary artery atherosclerosis with atherosclerosis of the intracranial cerebral artery and the extracranial carotid artery. Eur Neurol 2008; 59: 292-8. [Crossref]

12. Di Pasquale G, Andreoli A, Pinelli G, Grazi P, Manini G, Tognetti F, et al. Cerebral ischemia and asymptomatic coronary artery disease: a prospective study of 83 patients. Stroke 1986; 17: 1098-101. [Crossref]

13. Kim JG, Lee SJ, Choi H, Choi YJ, Lee BH. Silent Coronary Artery Disease in Symptomatic Candidates for Carotid Revascularization Intervention. Eur Neurol 2016; 76: 69-74. [Crossref]

14. Enomoto $Y$, Yoshimura S, Yamada K, Kawasaki M, Nishigaki K, Minatoguchi $S$, et al. Silent coronary artery disease in Japanese patients undergoing carotid artery stenting. J Stroke Cerebrovasc Dis 2013; 22: 1163-8. [Crossref]

15. Hofmann R, Kypta A, Steinwender C, Kerschner K, Grund M, Leisch F. Coronary angiography in patients undergoing carotid artery stenting shows a high incidence of significant coronary artery disease. Heart 2005; 91: 1438-41. [Crossref]

16. Hertzer NR, Young JR, Beven EG, Graor RA, O'Hara PJ, Ruschhaupt WF 3rd, et al. Coronary angiography in 506 patients with extracranial cerebrovascular disease. Arch Intern Med 1985; 145: 849-52. [Crossref]

17. Sulženko J, Paluszek P, Machnik R, Widimský P, Jarkovský J, Pieniazek P. Prevalence and predictors of coronary artery disease in patients undergoing carotid artery stenting. Coron Artery Dis 2019; 30: 204-10. [Crossref]

18. Amarenco P, Bogousslavsky J, Callahan A 3rd, Goldstein LB, Hennerici M, Rudolph AE, et al.; Stroke Prevention by Aggressive Reduction in Cholesterol Levels (SPARCL) Investigators. High-dose atorvastatin after stroke or transient ischemic attack. N Engl J Med 2006; 355: 549-59. [Crossref] 
19. Dhamoon MS, Sciacca RR, Rundek T, Sacco RL, Elkind MS. Recurrent stroke and cardiac risks after first ischemic stroke: the Northern Manhattan Study. Neurology 2006; 66: 641-6. [Crossref]

20. Adams RJ, Chimowitz MI, Alpert JS, Awad IA, Cerqueria MD, Fayad $P$, et al.; Stroke Council and the Council on Clinical Cardiology of the
American Heart Association; American Stroke Association. Coronary risk evaluation in patients with transient ischemic attack and ischemic stroke: a scientific statement for healthcare professionals from the Stroke Council and the Council on Clinical Cardiology of the American Heart Association/American Stroke Association. Circulation 2003; 108: 1278-90. [Crossref] 